\title{
Long-COVID-19 Symptoms after Infection in COVID Long-Haulers
}

\author{
Stefania Pellino1, Margherita Luciano'1, Rosamaria Luciano', Erika Mancini' ${ }^{1}$, \\ Maria Concetta Conte ${ }^{2}$, Gennaro Volpe ${ }^{3}$, Tommaso Zerella ${ }^{1}$ \\ ${ }^{1}$ Department of Prevention, Azienda Sanitaria Locale (ASL) Benevento, Benevento, Italy \\ ${ }^{2}$ Health Direction, Azienda Sanitaria Locale (ASL) Benevento, Benevento, Italy \\ ${ }^{3}$ General Direction, Azienda Sanitaria Locale (ASL) Benevento, Benevento, Italy \\ Email: stefaniapellino89@gmail.com
}

How to cite this paper: Pellino, S., Luciano, M., Luciano, R., Mancini, E., Conte, M.C., Volpe, G. and Zerella, T. (2021) LongCOVID-19 Symptoms after Infection in COVID Long-Haulers. Open Journal of Epidemiology, 11, 473-482.

https://doi.org/10.4236/ojepi.2021.114038

Received: September 13, 2021

Accepted: November 19, 2021

Published: November 22, 2021

Copyright (c) 2021 by author(s) and Scientific Research Publishing Inc. This work is licensed under the Creative Commons Attribution International License (CC BY 4.0).

http://creativecommons.org/licenses/by/4.0/

\begin{abstract}
The negative molecular swab does not mean that the body and mind are healed: even months after Sars-CoV-2 infection, patients may continue to have symptoms. The symptoms mainly present at $6-12$ months in patients recovered from COVID-19 are: asthenia, breathlessness, difficulty in breathing deeply, myalgia, psychological disorders and difficulty in concentrating such as "brain fog". The study was conducted from June 2021 to July 2021 at Health Prevention Department in Benevento (Campania Region, South Italy). 133 patients accepted the questionnaire in the form of a telephone interview. The purpose of this study is precisely to highlight how, although a year after infection, a number of patients still show post-COVID symptoms. In particular, 77 out of 133 positive patients became Long-Haulers (58\%).
\end{abstract}

\section{Keywords}

COVID-19, Long-COVID, Long-Haulers

\section{Introduction}

On December 31, 2019, Chinese health authorities reported that an outbreak of atypical pneumonia of unknown aetiology had developed in the city of Wuhan (Hubei province, central-eastern China). Many of the initial cases reported attendance at the Wuhan wholesale fish market, where wild animals of disparate species are also for sale, used for food purposes. On January 9, 2020, the Chinese Center for Disease Control announced that it had identified the causative agent: a new coronavirus, first provisionally named $2019-\mathrm{nCoV}$ and officially named SARS-CoV2 by the International Committee on Taxonomy of Viruses on 11 February 2020, 
which was quickly sequenced and made available to the scientific community and subsequently confirmed the possibility of human-to-human transmission of the virus. Coronaviruses are a group of related RNA viruses common in many animal species (such as camels and bats) but in some cases, rarely, they can change and infect humans and then spread to the population, mainly causing the infections of upper respiratory tract and the gastrointestinal tract. The severity of these conditions is highly variable, since coronaviruses are responsible for both a large number of common cold syndromes and severe respiratory syndromes such as SARS (Severe Acute Respiratory Syndrome) and MERS (Middle East Respiratory Syndrome). They owe their name to the appearance of the virions at the electron microscope, linked to the presence of the $S$ proteins of the viral peplomer that create an image that resembles a royal crown or the solar corona [1]. The host receptor for SARS-CoV-2 cell entry is the Angiotensin-Converting Enzyme 2 (ACE2). SARS-CoV-2 binds to ACE2 through the receptor binding-domain of its spike protein and enters the cells. SARS-CoV-2 coronavirus was sequenced in mid-January by Chinese researchers and subsequently in other laboratories around the world, including Italy, one of the Lazzaro Spallanzani National Institute for Infectious Diseases. The results show that SARS-CoV-2 shares $79.5 \%$ of the gene sequence of the SARS coronavirus and $96.2 \%$ that of a bat coronavirus [2]. The animal species of origin (reservoir) has not yet been identified with certainty, although it is supposed to be bats of the Rhinolophus affinis species, with direct transmission to humans or with any other intermediate hosts (currently not identified). It is possible that the permanence of bats in close contact with other animals and with humans has favored mutations and the passage of species, again in analogy to what happened with other respiratory syndromes due to other Betacoronaviruses, but zoonotic transmission from the Wuhan fish market has not been established in all cases [3]. Like other viruses, SARS-CoV-2 mutates over time. Some variants have attracted particular attention due to their rapid spread within populations and evidence of increased transmissibility and possible "immune leak" [4]. The World Health Organization (WHO) has designated each variant with a nomenclature based on the Greek alphabet. Most mutations in the SARS-CoV-2 genome consist of changes in the amino acid sequence in the Spike protein that are associated with greater transmissibility and contagiousness of the virus.

The incubation period for the infection is estimated to be between 2 and 14 days, with an average of 5 days. The transmission potential of SARS-CoV-2 begins before the development of symptoms and is greatest at the onset of the disease [5]. Infected individuals are more likely to be contagious in the early stages of disease when levels of viral RNA detected by upper respiratory tract samples are highest (approximately two days before and one day after the onset of symptoms and decreased within seven days) [6]. Prolonged detection of viral RNA in respiratory specimens does not indicate prolonged infectivity and there appears to be a viral RNA level threshold below which infectivity is unlikely [7]. 
The risk of transmission from a SARS-CoV-2 infected individual varies with the type and duration of exposure, the use of preventive measures, and the likely individual factors (for example, the amount of virus present in respiratory secretions) [8]. In fact, the risk of transmission after contact with an individual with COVID-19 increases with proximity and duration of contact and appears higher with prolonged contact indoors [9]. Therefore, most secondary infections have been described among family contacts, in health care settings where personal protective equipment was not used (including hospitals, long-term care facilities) and in other congregational contexts where people reside or work in confined spaces [10].

The risk of transmission with more indirect contact (eg, passing someone on the street with an infection, handling objects that had previously been handled by someone with an infection) is not well established and is likely to be very low.

The most common symptoms of an upper respiratory tract infection by coronaviruses in humans include fever, cough, headache, pharyngodynia, difficult breathing, and general malaise for a short period of time [11]. In severe cases, the infection can cause pneumonia or Bronchopneumonia, severe acute respiratory syndrome, renal failure, up to death [12]. The involvement of the lower respiratory tract and complications are more frequent in people with pre-existing chronic diseases of the cardiovascular and/or respiratory system and in people with the impaired immune system, in infants and the elderly [13].

The picture of SARS-CoV-2 infection is that of acute viral pneumonia [14]. The onset symptoms of SARS-CoV-2 infection are rather non-specific and occur in a syndromic form in $90 \%$ of cases:

- hyperpyrexia even high, above $39^{\circ} \mathrm{C}$;

- generally dry cough, more rarely productive;

- malaise and asthenia;

- dyspnoea;

- pharyngodynia;

- headache;

- myalgia;

- anosmia and/or dysgeusia.

Unlike other human coronaviruses, gastrointestinal symptoms such as diarrhea, nausea and vomiting are rare.

COVID-19 pandemic has led to a growing population of individuals recovering from acute SARS-CoV-2 infection [15]. However, a number of these patients may experience a wide range of symptoms after recovery from acute illness, which is referred to by several terms including "Long-COVID", "post-COVID conditions" and Post-Acute Sequelae of SARS-CoV-2 Infection (PASC) [16].

Although there are no widely accepted definitions of the stages of recovery from COVID-19, the Centers for Disease Control and Prevention (CDC) has proposed the following categories:

- Acute COVID-19: symptoms of COVID-19, up to four weeks after the onset of the disease; 
- Post-COVID-19 conditions: a wide range of symptoms (physical and mental) that develop during or after COVID-19, continue for $\geq 4$ weeks and are not explained by an alternative diagnosis.

These phases reflect symptomatic recovery and are not related to active viral infection and infectivity [17].

\section{Materials and Methods}

This study was conducted on 133 patients, 60 females (45.1\%) and 73 males (54.9\%) with Sars-CoV-2 infection during the first wave of COVID-19 pandemic in Benevento, a city of Campania Region (South Italy). We proposed a questionnaire in the form of telephone interview to a group of 192 COVID-19 positive patients treated by Health Prevention Department. Only 133 patients accepted the interview. Interview was conducted from June 2021 to July 2021 after $11-12$ months of their recovery from the infection. The age of 133 patients ranged from 3 years to 91 years (Table 1); under-18 patients answered with parentals authorization. The patients, non-hospitalized, were classified into three groups: asymptomatic; paucisymptomatic (patients with anosmia and/or dysgeusia and/or asthenia and/or lowgrade fever and/or headache and/or myalgia); mild-moderate symptomatic (TB > $37.5^{\circ} \mathrm{C}$ and/or cough and/or dyspnea).

133 patients' positives from March 2020 to June 2020, were classified: 97 (73\%) were asymptomatic, 23 (17\%) pauci-symptomatic, 13 (10\%) with symptoms mildmoderate.

Patients answered questions about their symptoms, physical and mental, after their COVID-19 infection. They reported their clinical conditions after their recovery.

\section{Results}

Patients with Long COVID-19 symptoms are appointed as Long-Haulers. They Table 1. Characteristic of COVID-19 positive patients.

\begin{tabular}{cccc}
\hline Age & Male & Female & Total \\
\hline $0-9$ & 1 & 0 & 1 \\
$10-19$ & 6 & 6 & 12 \\
$20-29$ & 12 & 9 & 21 \\
$30-39$ & 10 & 4 & 14 \\
$40-49$ & 10 & 15 & 25 \\
$50-59$ & 17 & 17 & 34 \\
$60-69$ & 11 & 5 & 16 \\
$70-79$ & 1 & 1 & 2 \\
$80-89$ & 4 & 3 & 7 \\
$90+$ & 1 & 0 & 1 \\
Total & 73 & 60 & 133 \\
\hline
\end{tabular}


have exhibited symptoms even after their recovery (Table 2). In particular 77 of 133 positive patients are resulted Long-Haulers (58\%). In these patients the symptoms reported were: dyspnea (12\%), shortness of breath (21\%), chest pain or tightness (17\%), breathlessness (22\%) tachycardia (19\%), hypertension (1\%), anosmia and/or dysgeusia (23\%), skin rash (2\%), asthenia (57\%), headache (6\%), dizziness (5\%), osteoarticular pains (46\%), anxiety (27\%), depression (10\%), poor memory and concentration (25\%), brain fog (28\%), insomnia (7\%).

Pulmonary and cardiovascular manifestations were more frequently in patients with diabetes, bpco, and hypertension. Psychological symptoms, such as anxiety and depression, were more frequently in adolescent patients and the same in female gender. Cognitive symptoms were more frequently in asymptomatic patient.

\section{Discussion}

The negative molecular swab does not mean that the body and mind are healed: even months after Sars-CoV-2 infection, patients may continue to have symptoms [18]. The symptoms mainly present at $6-12$ months in patients recovered from

Table 2. Long-COVID-19 symptoms of positive patients.

\begin{tabular}{|c|c|}
\hline Physical Symptoms & $\%$ \\
\hline Dyspnea & $12 \%$ \\
\hline Shortness of Breath & $21 \%$ \\
\hline Chest Pain or Tightness & $17 \%$ \\
\hline Breathlessness & $22 \%$ \\
\hline Tachycardia & $19 \%$ \\
\hline Hypertension & $1 \%$ \\
\hline Anosmia and/or Dysgeusia & $23 \%$ \\
\hline Skin Rash & $2 \%$ \\
\hline Asthenia & $57 \%$ \\
\hline Headache & $6 \%$ \\
\hline Dizziness & $5 \%$ \\
\hline Osteoarticular Pains & $46 \%$ \\
\hline \multicolumn{2}{|l|}{ Psychological Symptoms } \\
\hline Anxiety & $27 \%$ \\
\hline Depression & $10 \%$ \\
\hline \multicolumn{2}{|l|}{ Cognitive Symptoms } \\
\hline Poor Memory and Concentration & $25 \%$ \\
\hline Brain Fog & $28 \%$ \\
\hline Insomnia & $7 \%$ \\
\hline
\end{tabular}


COVID-19 are: asthenia, breathlessness, difficulty in breathing deeply, myalgia but also psychological disorders and difficulty in concentrating such as "brain fog" [19].

\section{Pulmonary manifestation}

Patients who have been affected by SARS-CoV-2 interstitial pneumonia may develop fibrosis irreversibile and fibrotic interstitial disease [20]. This is due to the persistence of chronic inflammation [21]. However, the abnormal lung function may be reversible with time or with treatments [22]. Even in patients asymptomatic to COVID infection, the presence of pulmonary opacities on CT is observed in some cases [23]. It is still to be assessed whether the persistence of these lesions will remain over time [24].

\section{Cardiovascular and hematologic manifestations}

Various cardiovascular complications have been associated in COVID-19 patients such as hypotension, cardiomegaly, bradycardia and tachycardia [25]. However, most of the complications have returned to normal after 3 - 4 weeks of healing, with the exception of tachycardia which is present after 6 - 12 months even in patients who have been affected by COVID-19 in a paucysymptomatic status

[26]. Furthermore, the release of pro-inflammatory cytokines, which occurs in COVID-19 infection, increases the risk of hypertension and cardiovascular problems [27]. Chronic inflammatory state, the release of pro-thrombotic factors and the endothelitis that develop during SAR-CoV-2, increases the possibility of venous and arterial thrombotic complications [28]. In addition, the increase in the expression of the ACE2 enzyme at the level of the endothelial cells that occurs during infection and continues healing thereafter, increases the thrombotic and inflammatory state [29].

\section{Renal manifestations}

Acute renal failure has been reported in many patients with severe conditions of SARS-CoV-2 infection, this underlines how COVID-19 can be a systemic disease and not just lung disease [30]. Other kidney impairments observed are hematuria and proteinuria [31]. However, in patients at home and therefore in mildmoderate conditions [32], we did not observe kidney impairments as a consequence of the infection [33].

\section{Gastrointestinal manifestations}

Gastrointestinal disorders, after respiratory ones, are the most present in patients with COVID-19, even in cases where no other symptoms occur [34]. In particular, patients experience anorexia, nausea, abdominal pain, diarrhea [35]. The presence of SARS-CoV-2 viral particles was observed in the faeces and damage to the gastrointestinal and hepatic mucosa was observed in subjects affected [36]. The long-term gastrointestinal symptoms that have been most observed are difficulty in digestion and a sense of heaviness after meals [37].

\section{Neurological and psychosocial manifestations}

In cases of severe infections, stroke is associated with the increase in thrombotic risk [38]. In mild-moderate infections, we observe more frequently the pres- 
ence of polyneuropathies, hyposmia, headache, weakness and altered consciousness [39]. Another common symptom is difficulty thinking clearly and memory deficits [40]. It is not yet established whether this may be due to a direct action of the virus on neurons [41]. The most frequent consequences in patients with mild, moderate or severe COVID-19 are psychological disturbances [42]. Depressive syndromes and anxiety syndromes occur mainly in women. And the presence of these syndromes should not be underestimated even in young patients, especially in the adolescent phase [43]. The lockdown, isolation in the event of positivity, the zeroing of social and often working life, has created psychological and social problems with enormous difficulty also in reintegrating into the world of work [44].

\section{Conclusion}

SARS-CoV-2, the virus that causes COVID-19, was identified in December 2019. There is still a lot to learn about it, but our understanding of the virus and COVID19 is evolving by the day. Researchers will learn more about how and why the coronavirus affects different people in such a variety of ways, and why some people experience no symptoms at all while others have life-threatening organ damage or lasting disability. New insights will provide avenues for therapies and hope for people living with long-term COVID-19 effects.

\section{Conflicts of Interest}

The authors declare no conflicts of interest regarding the publication of this paper.

\section{References}

[1] Li, Q., Guan, X., et al. (2020) Early Transmission Dynamics in Wuhan, China, of Novel Coronavirus-Infected Pneumonia. The New England Journal of Medicine, 382, 1199-1207.

[2] Wuhan City Health Committee (WCHC) (2020) Wuhan Municipal Health and Health Commission's Briefing on the Current Pneumonia Epidemic Situation in Our City 2019.

[3] Tan, W.J., Zhao, X., Ma, X.J., Wang, W.L., Niu, P.H., Xu, W.B., Gao, G.F. and Wu., G.Z. (2020) A Novel Coronavirus Genome Identified in a Cluster of Pneumonia Cases-Wuhan, China 2019-2020. China CDC Weekly, 2, 61-62. https://doi.org/10.46234/ccdcw2020.017

[4] Zhu, N., Zhang, D., et al. (2019) A Novel Coronavirus from Patients with Pneumonia in China, 2019. The New England Journal of Medicine, 382, 727-733.

[5] Fang, L., Karakiulakis, G. and Roth, M. (2020) Are Patients with Hypertension and Diabetes Mellitus at Increased Risk for COVID-19 Infection? The Lancet Respiratory Medicine, 8, e21. https://doi.org/10.1016/S2213-2600(20)30116-8

[6] Holmes, E. (2020) Initial Genome Release of Novel Coronavirus.

[7] Zhou, P., Yang, X.L., Wang, X.G., et al. (2020) A Pneumonia Outbreak Associated with a New Coronavirus of Probable Bat Origin. Nature, 579, 270-273. https://doi.org/10.1038/s41586-020-2012-7 
[8] Lu, R., Zhao, X., et al. (2020) Genomic Characterisation and Epidemiology of 2019 Novel Coronavirus: Implications for Virus Origins and Receptor Binding. The Lancet, 395, 565-574. https://doi.org/10.1016/S0140-6736(20)30251-8

[9] WHO (2021) Tracking SARS-CoV-2 Variants. https://www.who.int/en/activities/tracking-SARS-CoV-2-variants/

[10] WHO (2020) Report of the WHO-China Joint Mission on Coronavirus Disease 2019 (COVID-2019).

http://www.who.int/docs/default-source/coronaviruse/who-china-joint-mission-on -covid-19-final-report.pdf

[11] Zou, L., Ruan, F., Huang, M., et al. (2020) SARS-CoV-2 Viral Load in Upper Respiratory Specimens of Infected Patients. The New England Journal of Medicine, 382, 1177-1179. https://doi.org/10.1056/NEJMc2001737

[12] To, K.K., Tsang, O.T., Leung, W.S., et al. (2020) Temporal Profiles of Viral Load in Posterior Oropharyngeal Saliva Samples and Serum Antibody Responses during Infection by SARS-CoV-2: An Observational Cohort Study. The Lancet. Infectious Diseases, 20, 565-574. https://doi.org/10.1016/S1473-3099(20)30196-1

[13] Wölfel, R., Corman, V.M., Guggemos, W., et al. (2020) Virological Assessment of Hospitalized Patients with COVID-2019. Nature, 581, 465-469.

https://doi.org/10.1038/s41586-020-2196-X

[14] He, X., Lau, E.H.Y., Wu, P., et al. (2020) Temporal Dynamics in Viral Shedding and Transmissibility of COVID-19. Nature Medicine, 26, 672-675. https://doi.org/10.1038/s41591-020-0869-5

[15] COVID-19 Investigation Team (2020) Clinical and Virologic Characteristics of the First 12 Patients with Coronavirus Disease 2019 (COVID-19) in the United States. Nature Medicine, 26, 861-868. https://doi.org/10.1038/s41591-020-0877-5

[16] Jones, T.C., Biele, G., Mühlemann, B., et al. (2021) Estimating Infectiousness throughout SARS-CoV-2 Infection Course. Science, 373, Article ID: eabi5273. https://doi.org/10.1126/science.abi5273

[17] Cevik, M., Marcus, J.L., Buckee, C. and Smith, T.C. (2021) Severe Acute Respiratory Syndrome Coronavirus 2 (SARS-CoV-2) Transmission Dynamics Should Inform Policy. Clinical Infectious Diseases, 73, S170-S176.

https://doi.org/10.1093/cid/ciaa1442

[18] Fung, H.F., Martinez, L., Alarid-Escudero, F., Salomon, J.A, Studdert, D.M., Andrews, J.R., Goldhaber-Fiebert, J.D., Stanford-CIDE Coronavirus Simulation Model (SCCOSMO) Modeling Group (2021) The Household Secondary Attack Rate of Severe Acute Respiratory Syndrome Coronavirus 2 (SARS-CoV-2): A Rapid Review. Clinical Infectious Diseases, 73, S138-S145. https://doi.org/10.1093/cid/ciaa1558

[19] Ooi, E.E. and Low, J.G. (2020) Asymptomatic SARS-CoV-2 Infection. The Lancet Infectious Diseases, 20, 996-998. https://doi.org/10.1016/S1473-3099(20)30460-6

[20] Lavezzo, E., Franchin, E., Ciavarella, C., et al. (2020) Suppression of a SARS-CoV-2 Outbreak in the Italian Municipality of Vo'. Nature, 584, 425-429.

[21] McMichael, T.M., Clark, S., Pogosjans, S., et al. (2020) COVID-19 in a Long-Term Care Facility-King County, Washington, February 27-March 9, 2020. Morbidity and Mortality Weekly Report, 69, 339-342. https://doi.org/10.15585/mmwr.mm6912e1

[22] Ghinai, I., Woods, S., Ritger, K.A., et al. (2020) Community Transmission of SARSCoV-2 at Two Family Gatherings-Chicago, Illinois, February-March 2020. Morbidity and Mortality Weekly Report, 69, 446-450. 
https://doi.org/10.15585/mmwr.mm6915e1

[23] Rothe, C., Schunk, M., Sothmann, P., et al. (2020) Transmission of 2019-nCoV Infection from an Asymptomatic Contact in Germany. The New England Journal of Medicine, 382, 970-971. https://doi.org/10.1056/NEJMc2001468

[24] Yu, P., Zhu, J., Zhang, Z. and Han, Y. (2020) A Familial Cluster of Infection Associated with the 2019 Novel Coronavirus Indicating Possible Person-to-Person Transmission During the Incubation Period. The Journal of Infectious Diseases, 221, $1757-$ 1761. https://doi.org/10.1093/infdis/jiaa077

[25] Bai, Y., Yao, L., Wei, T., Tian, F., Jin, D.-Y., Chen, L.J. and Wang, M.Y. (2020) Presumed Asymptomatic Carrier Transmission of COVID-19. The Journal of the American Medical Association, 323, 1406-1407. https://doi.org/10.1001/jama.2020.2565

[26] Hu, Z., Song, C., Xu, C., Jin, G., Chen, Y., Xu, X., Ma, H., Chen, W., Lin, Y., Zheng, Y., Wang, J., Hu, Z., Yi, Y. and Shen, H. (2020) Clinical Characteristics of 24 Asymptomatic Infections with COVID-19 Screened among Close Contacts in Nanjing, China. Science China Life Sciences, 63, 706-711. https://doi.org/10.1007/s11427-020-1661-4

[27] Qian, G., Yang, N., Ma, A.H.Y., Wang, L., Li, G., Chen, X. and Chen, X. (2020) COVID-19 Transmission within a Family Cluster by Presymptomatic Carriers in China. Clinical Infectious Diseases, 71, 861-862. https://doi.org/10.1093/cid/ciaa316

[28] Böhmer, M.M., Buchholz, U., Corman, V.M., et al. (2020) Investigation of a COVID-19 Outbreak in Germany Resulting from a Single Travel-Associated Primary Case: A Case Series. The Lancet: Infectious Diseases, 20, 920-928. https://doi.org/10.1016/S1473-3099(20)30314-5

[29] Wang, Y., He, Y., Tong, J., Qin, Y., Xie, T., Li, J., Li, J., Xiang, J., Cui, Y., Higgs, E.S. and Xiang, J. (2020) Characterization of an Asymptomatic Cohort of Severe Acute Respiratory Syndrome Coronavirus 2 (SARS-CoV-2) Infected Individuals Outside of Wuhan, China. Clinical Infectious Diseases, 71, 2132-2138. https://doi.org/10.1093/cid/ciaa629

[30] Madewell, Z.J., Yang, Y., Longini, I.M., Halloran, M.E. and Dean, N.E. (2020) Household Transmission of SARS-CoV-2: A Systematic Review and Meta-Analysis. JAMA Network Open, 3, e2031756. https://doi.org/10.1001/jamanetworkopen.2020.31756

[31] Li, F., Li, Y.Y., Liu, M.J., et al. (2021) Household Transmission of SARS-CoV-2 and Risk Factors for Susceptibility and Infectivity in Wuhan: A Retrospective Observational Study. The Lancet: Infectious Diseases, 21, 617-628. https://doi.org/10.1016/S1473-3099(20)30981-6

[32] Wei, W.E., Li, Z., Chiew, C.J., Yong, S.E., Toh, M.P. and Lee, V.J. (2020) Presymptomatic Transmission of SARS-CoV-2-Singapore, January 23-March 16, 2020. Morbidity and Mortality Weekly Report, 69, 411-415. https://doi.org/10.15585/mmwr.mm6914e1

[33] Buitrago-Garcia, D., Egli-Gany, D., Counotte, M.J., Hossmann, S., Imeri, H., Ipekci, A.M., Salanti, G. and Low, N. (2020) Occurrence and Transmission Potential of Asymptomatic and Presymptomatic SARS-CoV-2 Infections: A Living Systematic Review and Meta-Analysis. PLoS Medicine, 17, e1003346. https://doi.org/10.1371/journal.pmed.1003346

[34] Plucinski, M.M., Wallace, M., Uehara, A., et al. (2021) Malattia di coronavirus 2019 (COVID-19) negli americani a bordo della nave da crociera Diamond Princess. Clinical Infectious Diseases, 72, e448.

[35] Luo, L., Liu, D., Liao, X., et al. (2020) Contact Settings and Risk for Transmission in 3410 
Close Contacts of Patients With COVID-19 in Guangzhou, China: A Prospective Cohort Study. Annals of Internal Medicine, 173, 879-887. https://doi.org/10.7326/M20-2671

[36] European Center for Disease Control (ECDC) (2020) Rapid Risk Assessment: Outbreak of Acute Respiratory Syndrome Associated with a Novel Coronavirus, China: First Local Transmission in the EU/EEA-Third Update.

[37] Lee, S., Kim, T., Lee, E., et al. (2020) Clinical Course and Molecular Viral Shedding among Asymptomatic and Symptomatic Patients with SARS-CoV-2 Infection in a Community Treatment Center in the Republic of Korea. JAMA Internal Medicine, 180, 1447-1452. https://doi.org/10.1001/jamainternmed.2020.3862

[38] Huang, C., Wang, Y., et al. (2020) Clinical Features of Patients Infected with 2019 Novel Coronavirus in Wuhan, China. The Lancet, 395, 497-506.

[39] Oran, D.P. and Topol, E.J. (2020) Prevalence of Asymptomatic SARS-CoV-2 Infection: A Narrative Review. Annals of Internal Medicine, 173, 362-367. https://doi.org/10.7326/M20-3012

[40] Chan, J., Yuan, S., et al. (2020) A Familial Cluster of Pneumonia Associated with the 2019 Novel Coronavirus Indicating Personto-Person Transmission: A Study of a Family Cluster. The Lancet, 395, 514-523. https://doi.org/10.1016/S0140-6736(20)30154-9

[41] Chang, D., Lin, M.G., et al. (2020) Epidemiologic and Clinical Characteristics of Novel Coronavirus Infections Involving 13 Patients outside Wuhan, China. The Journal of the American Medical Association, 323, 1092-1093. https://doi.org/10.1001/jama.2020.1623

[42] Wang, D., Hu, B., Hu, C., et al. (2020) Clinical Characteristics of 138 Hospitalized Patients with 2019 Novel Coronavirus-Infected Pneumonia in Wuhan, China. The Journal of the American Medical Association, 323, 1061-1069. https://doi.org/10.1001/jama.2020.1585

[43] Chen, N., Zhou, M., et al. (2020) Epidemiological and Clinical Characteristics of 99 Cases of 2019 Novel Coronavirus Pneumonia in Wuhan, China: A Descriptive Study. The Lancet, 395, 507-513. https://doi.org/10.1016/S0140-6736(20)30211-7

[44] Centers for Disease Control and Prevention (2021) Evaluating and Caring for Patients with Post-COVID Conditions: Interim Guidance.

https://www.cdc.gov/coronavirus/2019-ncov/hcp/clinical-care/post-covid-index.html 